\title{
Post-Traumatic Endophthalmitis Caused by Oerskovia turbata
}

\author{
Landon J. Rohowetz ${ }^{a} \quad N^{2}$ imesh A. Patel ${ }^{b} \quad$ Nicolas A. Yannuzzi ${ }^{b}$ \\ Kenneth C. Fan ${ }^{b}$ Darlene Miller ${ }^{b}$ Harry W. Flynn Jr. ${ }^{b}$ \\ aUniversity of Missouri - Kansas City School of Medicine, Kansas City, MO, USA; \\ ${ }^{b}$ Department of Ophthalmology, Bascom Palmer Eye Institute, Miami, FL, USA
}

\section{Keywords}

Oerskovia turbata · Post-traumatic endophthalmitis · Lensectomy · Capsulectomy

\begin{abstract}
Purpose: To present a previously unreported cause of bacterial endophthalmitis manifesting as delayed post-traumatic endophthalmitis ultimately responsive to total capsulectomy. Case Report: A patient presented with chronic endophthalmitis that occurred after ocular trauma with organic material and Oerskovia turbata was eventually isolated. After a prolonged treatment course, including two pars plana vitrectomies and total capsulectomy, the patient achieved 20/80 visual acuity at 1 -year follow-up. Conclusion: This is the first reported patient with endophthalmitis due to $O$. turbata, a Gram-positive bacillus found in soil that rarely causes human infection. The infection had a delayed presentation despite early prophylactic antibiotics and was ultimately eliminated with total capsulectomy. Removal of lens and lens capsule may be necessary in the management of post-traumatic endophthalmitis unresponsive to more conservative therapy, particularly in cases involving atypical organisms and lens capsule violation.




\section{Case Reports in Ophthalmology}

\section{Introduction}

Oerskovia turbata is a Gram-positive bacillus most commonly found in soil and first reported in $1954[1,2]$. Human infection with 0 . turbata is rare, and most reported cases have occurred in the setting of immunocompromise or implanted foreign bodies [3-6].

Trauma is a common setting for endophthalmitis [7]. The most common agents causing post-traumatic endophthalmitis are Staphylococcus and Streptococcus species [8], although Gram-positive bacilli have been associated with post-traumatic endophthalmitis involving potential soil contamination [7]. Endophthalmitis caused by 0 . turbata is described in this report.

\section{Case Report}

A 49-year-old male presented to the emergency department at Bascom Palmer Eye Institute complaining of right eye pain and decreased vision about $17 \mathrm{~h}$ after being struck in the eye with a tree branch. On examination, he was noted to have a $1.5-\mathrm{mm}$ corneal laceration with fibrin in the anterior chamber and signs of traumatic cataract with posterior synechiae and pigment on the anterior lens capsule. No signs of endophthalmitis were noted on B-scan. The laceration was repaired, and the patient was treated prophylactically with intravitreal ceftazidime $2.25 \mathrm{mg}$, vancomycin $1 \mathrm{mg}$, and voriconazole $50 \mu \mathrm{g}$. Aqueous humor cultures for fungi and bacteria were negative, and B-scan was unremarkable at initial follow-up.

After an initially uncomplicated postoperative course, the patient returned 26 days later with pain and an elevated intraocular pressure (IOP) of $45 \mathrm{~mm} \mathrm{Hg}$. On B-scan, there were mobile subhyaloid and vitreous opacities indicative of endophthalmitis (Fig. 1). The patient underwent pars plana lensectomy and vitrectomy with 1,000 cSt silicone oil injection, peripheral iridectomy, and administration of intravitreal vancomycin $1 \mathrm{mg}$, ceftazidime $2.25 \mathrm{mg}$, and voriconazole $100 \mu \mathrm{g}$. The lens capsule was left in place. The undiluted intraoperative vitreous sample demonstrated Gram-variable bacilli which were later identified as 0 . turbata.

The immediate post-treatment course was uncomplicated. However, 1 month later, the patient returned with decreased vision and an acutely-elevated IOP of $55 \mathrm{~mm} \mathrm{Hg}$. The patient underwent silicone oil removal.

The course was again stable for another 2 months until the patient presented with worsening eye pain and inflammation with an IOP of $45 \mathrm{~mm} \mathrm{Hg}$, keratic precipitates, and 4+ anterior chamber cell. B-scan demonstrated dense vitreous opacities with multiple focal hyperechoic foci and peripheral membrane formation. Ultrasound biomicroscopy revealed diffuse anterior chamber opacities and retained lens capsule adherent to the posterior iris (Fig. 2). Intravitreal vancomycin $1 \mathrm{mg}$ and ceftazidime $2.25 \mathrm{mg}$ were administered. Anterior chamber paracentesis was performed, culture of which revealed no fungal or bacterial growth. B-scan about 1 month later revealed new vitreous opacities and inferior membranes. The patient was suspected to have chronic endophthalmitis and subsequently underwent pars plana vitrectomy and total capsulectomy with administration of intravitreal vancomycin $1 \mathrm{mg}$, ceftazidime $2.25 \mathrm{mg}$, and voriconazole $100 \mu \mathrm{g}$. Anterior chamber fluid cultures were ultimately negative, and no further organisms were identified in the lens capsule on pathology. The patient had sustained mixed mechanism chronic IOP elevation and eventually underwent glaucoma drainage implant surgery. The final aphakic best corrected visual acuity was 20/80 and IOP was $19 \mathrm{~mm} \mathrm{Hg}$. There have been no reactivations of inflammation or infection for 1 year after the last surgery (Fig. 3). 


\section{Case Reports in Ophthalmology}

\section{Discussion}

The bacterium isolated in this patient, 0 . turbata, has rarely been reported to cause human infections, and has previously not been reported as a cause of endophthalmitis. The organism is Gram-positive, rod-shaped, with branching filaments that may break up into motile bacilli. There are only seven reports of human infection with 0 . turbata, which include catheter-related bacteremia [3, 6], prosthetic valve endocarditis [4, 9], acalculous cholecystitis [2], peritonitis [10], and an axillary abscess [5].

Trauma accounts for up to $25-30 \%$ of infectious endophthalmitis [7]. In reported large series, the incidence of endophthalmitis after open globe injury generally ranges from 3 to $5 \%$ [11-19] and may be higher in the setting of soil contamination [20]. As O. turbata is found in soil and grass cuttings [21], this patient demonstrates that atypical organisms must be considered in chronic, indolent endophthalmitis when the infection source is known to be organic matter [22, 23]. In prior reports of infections with 0 . turbata, there has been a high frequency of recurrence. It was similar in this case, where there were multiple relapses of inflammation and elevated IOP.

Disruption of the crystalline lens is a significant risk factor for endophthalmitis after penetrating trauma and may be present in up to $86-92 \%$ of patients with post-traumatic endophthalmitis [14, 24, 25]. Furthermore, endophthalmitis involving lens capsule violation is often less responsive to intravitreal antibiotics, potentially because of the disruption of normal aqueous humor flow or sequestration of microorganisms in retained lens material [14, 24, 26 28]. Ruptured lens material may also serve as a source of nutrition for organisms introduced into the eye during trauma [14].

While intraocular lens (IOL) placement after penetrating trauma involving lens capsule violation is a risk factor for subsequent development of endophthalmitis [17, 22], lensectomy without IOL placement may be associated with a reduced risk of endophthalmitis [24]. Therefore, removal of the lens and capsule without IOL placement may be considered in the initial treatment of open globe injury involving disruption of the lens capsule and in the treatment of post-traumatic endophthalmitis refractory to more conservative therapy [29].

The utility of total capsulectomy has been demonstrated in the treatment of endophthalmitis caused by Propionibacterium acnes, another Gram-positive rod-shaped organism known to cause delayed endophthalmitis unresponsive to antibiotics and standard vitrectomy due to its ability to be sequestered in the capsular bag [30,31]. This treatment modality may be appropriate in the management of endophthalmitis caused by other atypical organisms such as the one described in this patient. Indeed, lensectomy and capsulectomy were initially deferred in this patient but were ultimately performed in order to reduce the likelihood of recurrences.

In chronic endophthalmitis after penetrating trauma and open globe injury, retained intraocular foreign body (IOFB) must be considered $[16,28]$. In this instance, IOFB was ruled out with both anterior and posterior segment echography that demonstrated no signs of remaining foreign material.

\section{Conclusion}

A patient with chronic recurrent endophthalmitis caused by 0 . turbata presented with an indolent course after open globe injury that ultimately resolved after total capsulectomy. In addition to describing a previously unreported cause of infectious endophthalmitis, this case 
illustrates the importance of lens and lens capsule removal in the management of persistent or recurrent endophthalmitis involving atypical organisms and lens capsule violation.

\section{Statement of Ethics}

The authors have no ethical conflicts to disclose.

\section{Disclosure Statement}

The authors have no conflicts of interest to declare.

\section{Funding Sources}

The Department of Ophthalmology receives grant support from the NIH Center Core Grant P30EY014801 (Bethesda, MD) and the Research to Prevent Blindness Unrestricted Grant to UM.

\section{Author Contributions}

Landon J. Rohowetz: data analysis and interpretation, manuscript drafting, and literature search. Nimesh A. Patel and Nicolas A. Yannuzzi: manuscript drafting and revision. Kenneth C. Fan and Darlene Miller: patient assessment, data collection, and manuscript revisions. Harry W. Flynn Jr.: manuscript conception, design, revision, and final approval.

\section{References}

1 Erikson D. Factors promoting cell division in a soft mycelial type of Nocardia: nocardia turbata n. sp. J Gen Microbiol. 1954 Oct;11(2):198-208.

2 Thomas M, Padmini SB, Govindan VK, Appalaraju B. Oerskovia turbata and Myroides species: rare isolates from a case of acalculus cholecystitis. Indian J Med Microbiol. 2007 Jul;25(3):297-8.

3 LeProwse CR, McNeil MM, McCarty JM. Catheter-related bacteremia caused by Oerskovia turbata. J Clin Microbiol. 1989 Mar;27(3):571-2.

4 Reller LB, Maddoux GL, Eckman MR, Pappas G. Bacterial endocarditis caused by Oerskovia turbata. Ann Intern Med. 1975 Nov;83(5):664-6.

5 Reina J, Llompart I, Altés J. [An axillary abscess produced by Oerskovia turbata in an AIDS patient]. Rev Clin Esp. 1991 May;188(9):485-6.

6 Lair MI, Bentolila S, Grenet D, Cahen P, Honderlick P. Oerskovia turbata and Comamonas acidovorans bacteremia in a patient with AIDS. Eur J Clin Microbiol Infect Dis. 1996 May;15(5):424-6.

7 Gokce G, Sobaci G, Ozgonul C. Post-Traumatic Endophthalmitis: A Mini-Review. Semin Ophthalmol. 2015;30(5-6):470-4.

8 Cornut PL, Youssef B, Bron A, Thuret G, Gain P, Burillon C, et al.; French Institutional Endophthalmitis Study (FRIENDS) Group. A multicentre prospective study of post-traumatic endophthalmitis. Acta Ophthalmol. 2013 Aug;91(5):475-82.

9 Brown JM, Steigerwalt AG, Morey RE, Daneshvar MI, Romero LJ, McNeil MM. Characterization of clinical isolates previously identified as Oerskovia turbata: proposal of Cellulosimicrobium funkei sp. nov. and emended description of the genus Cellulosimicrobium. Int J Syst Evol Microbiol. 2006 Apr;56(Pt 4):801-4.

10 Betancourt Castellanos L, Ponz Clemente E, Fontanals Aymerich D, Blasco Cabañas C, Marquina Parra D, Grau Pueyo C, et al. [First case of peritoneal infection due to Oerskovia turbata (Cellulosimicrobium funkei)]. Nefrologia. 2011;31(2):223-5. 
11 Thompson JT, Parver LM, Enger CL, Mieler WF, Liggett PE; National Eye Trauma System. Infectious endophthalmitis after penetrating injuries with retained intraocular foreign bodies. Ophthalmology. 1993 Oct;100(10):1468-74.

12 Barr CC. Prognostic factors in corneoscleral lacerations. Arch Ophthalmol. 1983 Jun;101(6):919-24.

13 Duch-Samper AM, Menezo JL, Hurtado-Sarrió M. Endophthalmitis following penetrating eye injuries. Acta Ophthalmol Scand. 1997 Feb;75(1):104-6.

14 Thompson WS, Rubsamen PE, Flynn HW Jr, Schiffman J, Cousins SW. Endophthalmitis after penetrating trauma. Risk factors and visual acuity outcomes. Ophthalmology. 1995 Nov;102(11):1696-701.

15 Verbraeken H, Rysselaere M. Post-traumatic endophthalmitis. Eur J Ophthalmol. 1994 Jan-Mar;4(1):1-5.

16 Soheilian M, Rafati N, Mohebbi MR, Yazdani S, Habibabadi HF, Feghhi M, et al.; Traumatic Endophthalmitis Trial Research Group. Prophylaxis of acute posttraumatic bacterial endophthalmitis: a multicenter, randomized clinical trial of intraocular antibiotic injection, report 2. Arch Ophthalmol. 2007 Apr;125(4):460-5.

17 Andreoli CM, Andreoli MT, Kloek CE, Ahuero AE, Vavvas D, Durand ML. Low rate of endophthalmitis in a large series of open globe injuries. Am J Ophthalmol. 2009 Apr;147(4):601-8 e2.

18 Dehghani AR, Rezaei L, Salam H, Mohammadi Z, Mahboubi M. Post traumatic endophthalmitis: incidence and risk factors. Glob J Health Sci. 2014 Jun;6(6):68-72.

19 Banker TP, McClellan AJ, Wilson BD, Juan FM, Kuriyan AE, Relhan N, et al. Culture-positive endophthalmitis after open globe injuries with and without retained intraocular foreign bodies. Ophthalmic Surg Lasers Imaging Retina. 2017 Aug;48(8):632-7.

20 Boldt HC, Pulido JS, Blodi CF, Folk JC, Weingeist TA. Rural endophthalmitis. Ophthalmology. 1989 Dec;96(12):1722-6.

21 McNeil MM, Brown JM, Carvalho ME, Hollis DG, Morey RE, Reller LB. Molecular epidemiologic evaluation of endocarditis due to Oerskovia turbata and CDC group A-3 associated with contaminated homograft valves. J Clin Microbiol. 2004 Jun;42(6):2495-500.

22 Bhagat N, Nagori S, Zarbin M. Post-traumatic Infectious Endophthalmitis. Surv Ophthalmol. 2011 MayJun;56(3):214-51.

23 Maalouf F, Abdulaal M, Hamam RN. Chronic postoperative endophthalmitis: a review of clinical characteristics, microbiology, treatment strategies, and outcomes. Int J Inflamm. 2012;2012:313248.

24 Essex RW, Yi Q, Charles PG, Allen PJ. Post-traumatic endophthalmitis. Ophthalmology. 2004 Nov;111(11):2015-22.

25 Sabaci G, Bayer A, Mutlu FM, Karagül S, Yildirim E. Endophthalmitis after deadly-weapon-related open-globe injuries: risk factors, value of prophylactic antibiotics, and visual outcomes. Am J Ophthalmol. 2002 Jan;133(1):62-9.

26 Al-Mezaine HS, Al-Assiri A, Al-Rajhi AA. Incidence, clinical features, causative organisms, and visual outcomes of delayed-onset pseudophakic endophthalmitis. Eur J Ophthalmol. 2009 Sep-Oct;19(5):804-11.

27 Kanjee R, Koreishi AF, Tanna AP, Goldstein DA. Chronic postoperative endophthalmitis after cataract surgery secondary to vancomycin-resistant Ochrobactrum anthropi: case report and literature review. J Ophthalmic Inflamm Infect. 2016 Dec;6(1):25.

28 Ahmed Y, Schimel AM, Pathengay A, Colyer MH, Flynn HW Jr. Endophthalmitis following open-globe injuries. Eye (Lond). 2012 Feb;26(2):212-7.

29 Cebulla CM, Flynn HW Jr. Endophthalmitis after open globe injuries. Am J Ophthalmol. 2009 Apr;147(4):567-8.

30 Clark WL, Kaiser PK, Flynn HW Jr, Belfort A, Miller D, Meisler DM. Treatment strategies and visual acuity outcomes in chronic postoperative Propionibacterium acnes endophthalmitis. Ophthalmology. 1999 Sep;106(9):1665-70.

31 Shirodkar AR, Pathengay A, Flynn HW Jr, Albini TA, Berrocal AM, Davis JL, et al. Delayed- versus acute-onset endophthalmitis after cataract surgery. Am J Ophthalmol. 2012 Mar;153(3):391-8 e2. 


\section{Case Reports in Ophthalmology}

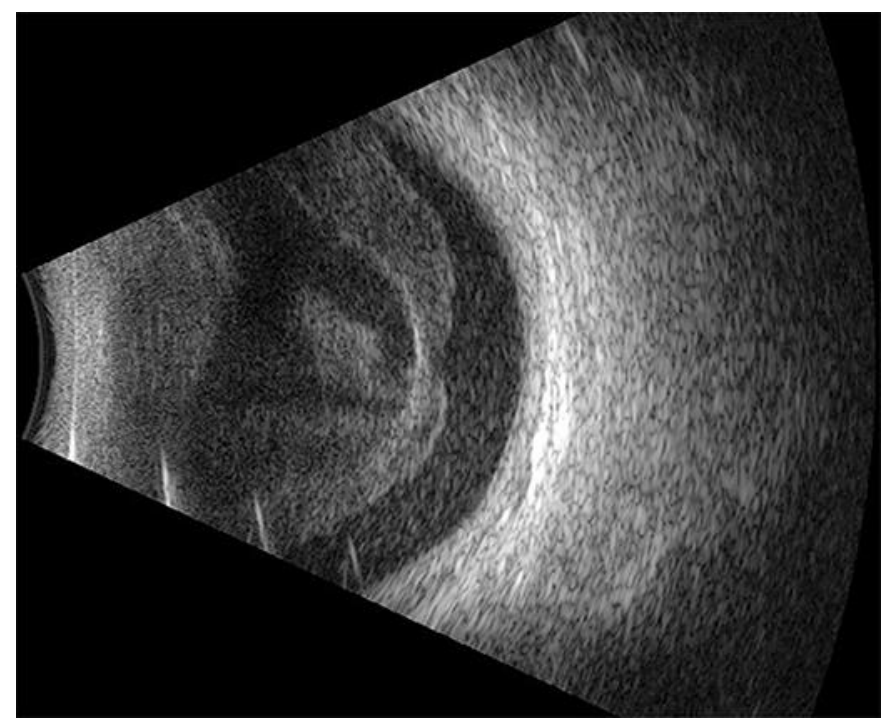

Fig. 1. B-scan 26 days after initial injury demonstrating total posterior vitreous detachment, choroidal thickening, and dense mobile subhyaloid and vitreous opacities indicative of endophthalmitis. There is no evidence of intraocular foreign body.

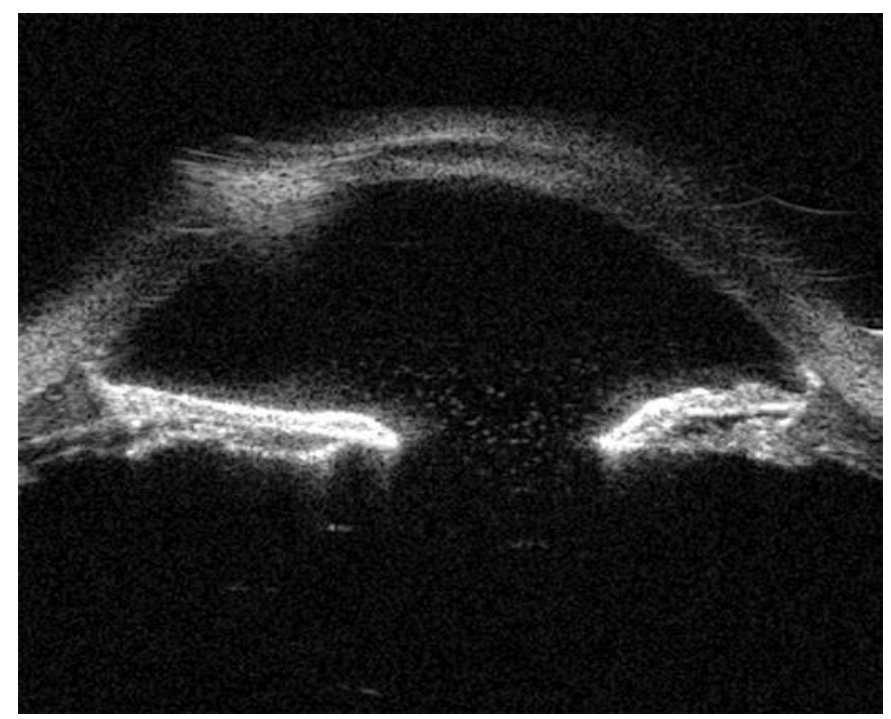

Fig. 2. Ultrasound biomicroscopy about 4 months after initial injury demonstrating retained lens capsule adherent to the posterior iris. 


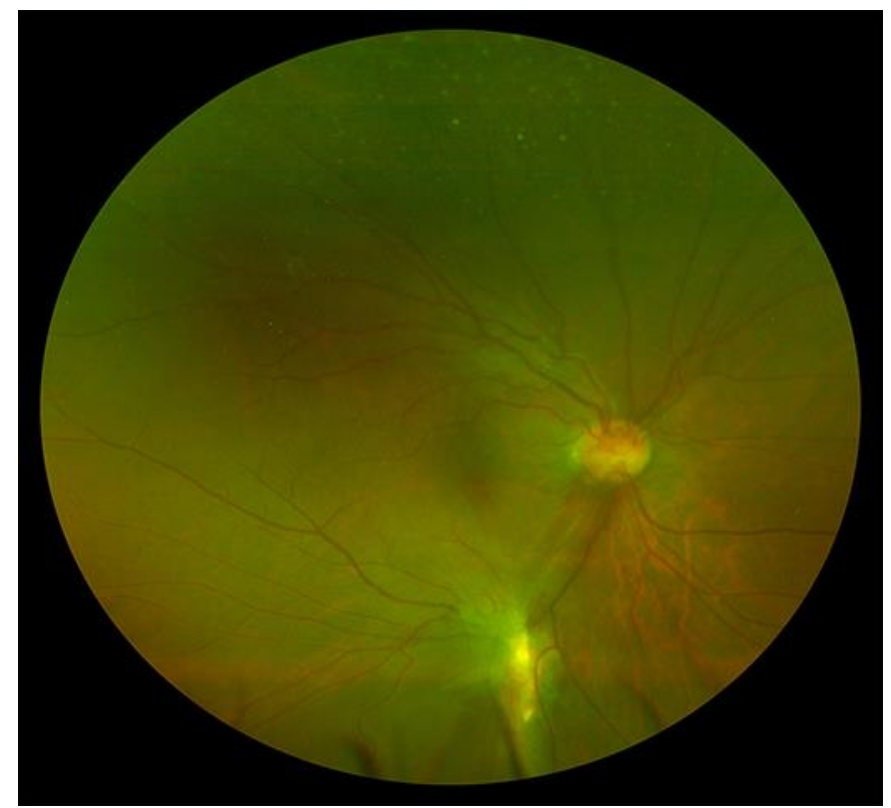

Fig. 3. Fundus photos 12 days post-vitrectomy demonstrating pre-retinal fibrosis and atrophy near the inferior vascular arcade. 